\title{
ABORTO PROVOCADO, EN EL INSTITUTO MATERNO INFANTIL
}

\author{
Dr. Luis Eduardo Santamaría Páez*
}

Hace ya algunos años que hemos dedicado especial interés al problema del aborto provocado en el Instituto Materno Infantil de Bogotá, en sus implicaciones clínicas y socio-culturales (2-3).

Los datos encontrados han sido comunicados en trabajos anteriores, la última vez en el Congreso Nacional de Cúcuta.

\section{Objetivo}

Esta comunicación tiene como objeto primordial transmitir datos estadísticos obtenidos en una laboriosa investigación continuada a lo largo de 5 años, a partir de 1965, que pretende cubrir el total de abortos ingresados al IMI. en dicho período de tiempo.

\section{Material y Métodos}

Las pacientes hospitalizadas en el IMI. al ser preparadas para la Comunión Sacramental son instruídas por las religiosas del Instituto (1), y en aquellas afectas de aborto en cualquiera de sus modalidades clínicas se inquiere sobre la presencia de maniobras abortivas, de la aplicación o administración de drogas $u$ otras sustancias, con la intención de interrumpir el embarazo.

Los resultados de esta encuesta se contabilizan día a día y son los que ahora vamos a mostrar.

\section{Criterio de clasificación}

Se han anotado todas las mujeres que en una $u$ otra forma buscaron atentar contra su embarazo, sin discernir de la efectividad o inocuidad del procedimiento escogido.

Se podría decir que esta es la contabilidad de las intenciones abortivas.

\section{Comentarios}

Es ciertamente sorprendente el número de abortos provocados en una $u$ otra forma, que como se muestra en el Cuadro № 1 se mantienen para el período en estudio alrededor del $80 \%$ con variaciones entre el $77 \%$ y el $87 \%$. No hay en las publicaciones a nuestro alcance ninguna que pueda compararse por la metodología seguida y es de anotar la variable incidencia que pudiera obtenerse aún dentro del mismo medio hospitalario según quienes se hayan encargado de las encuestas, ya que en el Servicio de Sépticas del mismo Instituto la investigación realizada por el personal médico tan solo arrojó un $67,2 \%$ sobre 665 pacientes tratadas en los 15 meses siguientes al 1\% de marzo de 1966 (3).

Los datos ahora presentados ofrecen una gran fiabilidad en cuanto que

* Profesor Asistente de Obstetricia y Ginecología de la Universidad Nacional de Bogotá. 
CUADRO N: 1

ABORTO UPROVOCADO. - DATOS OBTENIDOS POR LAS RELIGIOSAS DEL I.M.I. (1)

\begin{tabular}{lrrrrr}
\hline & 1965 & 1966 & 1967 & 1968 & $1969 *$ \\
\hline $\begin{array}{l}\text { Total abortos } \\
\text { Provocados }\end{array}$ & 4.738 & 5.555 & 5.529 & 5.545 & 4.202 \\
* Enero-Agosto & $87 \%$ & $82,9 \%$ & $83,5 \%$ & $77 \%$ & $83 \%$ \\
\hline
\end{tabular}

la forma de obtención y el personal encargado de las encuestas no podía tener interés alguno en alterar estos resultados.

Podría objetarse que la relación en forma de aborto provocado es excesiva en vista de la inocuidad 0 inefectividad de algunos de los métodos utilizados cuya discriminación no se cuantificó y por lo tanto no se puede analizar a cabalidad. La objeción ciertamente válida tiene una contra- respuesta en el hecho notorio de que el aspecto sobresaliente, el más valioso descle el punto de vista de actitud humana es el rechazo conciente de la gestación, la intención abortiva, el deseo de interrumpir un embarazo.

En el Cuadro № 2 mostramos datos estadísticos relacionados con la mortalidad materna en el IMI. comparada con la mortalidad por aborto.

\section{CUADRO № 2}

MORTALIDAD MATERNA. - MORTALIDAD POR ABORTO EN EL I.M.I.

\begin{tabular}{lccccc}
\hline & 1965 & 1966 & 1967 & 1968 & $1969 *$ \\
\hline $\begin{array}{l}\text { Mortalidad materna } \\
\text { Por aborto }\end{array}$ & $024 \%$ & $037 \%$ & $034 \%$ & $031 \%$ & $033 \%$ \\
$*$ Enero-Agosto & $26 \%$ & $45 \%$ & $43 \%$ & $49 \%$ & $54 \%$ \\
\hline
\end{tabular}

Es llamativo el incremento de la mortalidad por aborto que en 1965 era del $26 \%$ y para el año siguiente se eleva progresivamente hasta alcanzar un $54 \%$ en los primeros 8 meses del año 1969. Es evidente que el aumento global de la mortalidad se ha hecho a expensas del aborto.

\section{Soluciones}

Siempre nos ha parecido que la raíz del problema es la falta de educación. Educación integral que debe cubrir aspectos formales y prácticos. La educación sexual, la protección para la mujer embarazada, la paternidad responsable son elementos a con- siderar, recordando que la unidad moral requiere un mínimo de unidad socio-económica.

\section{Resumen y Conclusiones}

10. Se presentan datos obtenidos de Enero de 1965 a Agosto de 1969 por las religiosas del IMI. que muestran como el aborto provocado cubre el $77 \%$ al $78 \%$ del total de los ingresados al Instituto.

2. Se demuestra que la mortalidad por aborto ha aumentado del $26 \%$ en 1965 al 54\% en 1969.

3 . Se insiste en que la educación es el aspecto más importante de la lucha contra el aborto. 
Vol: $\mathbf{X X I}$

No 2

ABORTO PROVOCADO, EN EL INSTITUTO MATERNO INFANTIL 139

\section{BIBLIOGRAFIA}

1 ANA MARIA DE LCAMPO. Superiora Religiosa I.M.I. Comunicación personal.

2 SANTAMARIA P. L.: Aborto séptico y maniobras abortivas. Rev. Col. Obst. Ginec.
XVII, 273-290, Julio-Agosto 1966.

3 SANTAMARIA P. L., CASTRO M. G., LOZA-

NO C. A.: Aborto séptico, maniobras abortivas. Rev. Col. Obst. Ginec. XVIII, 381-404, Noviembre-Diciembre 1967. 